\title{
Africanidades em foco: as possibilidades da arte num projeto coletivo na Educação Infantil
}

Simoni Conceição Rodrigues Claudino

Recebido em: 15/05/2019

Aprovado em: 08/06/2019

DOI: 10.5965/2358092521212019009 


\section{RESUMO}

O presente artigo se apoia nas práticas educativas desenvolvidas em um Núcleo de Educação Infantil Municipal (NEIM) na cidade de Florianópolis, sobre a temática Africanidades. A todos os grupos de trabalho do NEIM foram propiciadas ações, interações, brincadeiras, pesquisas e explorações sensoriais. Com a temática definida, o NEIM se propôs a estudar e trazer experiências criativas na realização de diferentes brincadeiras, histórias e manifestações sobre diferentes povos que compõem a cultura africana e afro-brasileira. Os resultados obtidos revelam a infinidade de discussões e trabalhos que podem ser gerados junto a diferentes grupos de crianças na perspectiva da ampliação de conhecimentos e do respeito à diversidade cultural.

Palavras-chave: africanidades; arte; diversidade cultural.

\section{INTRODUZINDO A DISCUSSÃO DE UM PROJETO}

Este artigo trata de uma proposta desenvolvida no Núcleo de Educação Infantil Municipal Celso Pamplona, na cidade de Florianópolis. Esta instituição educativa tem como proposta de inserção de seus profissionais um grupo de trabalho que visa o desenvolvimento e planejamento dos chamados projetos coletivos. Este procedimento é comum em várias escolas, conforme aponta Corsino (2009, p. 112); "uma escola comporta vários tipos de projetos. A começar pelo projeto político-pedagógico que define a sua proposta".

No ano de 2018, tínhamos na unidade, de acordo com o Projeto Político Pedagógico (PPP), os seguintes projetos coletivos: horta, teatro, refeitório, parque, educação física e integração. Como o próprio nome indica, projetos coletivos são propostas 
de trabalho a serem apresentadas, vivenciadas e oportunizadas pelo coletivo da instituição, ou seja, aos seus doze grupos de trabalho. Algumas vezes a proposta envolve apenas dois ou três grupos, em outras estão todos juntos.

Para a organização das propostas os profissionais se comunicam através de grupos de mensagens de whatsapp, bem como realizam encontros quinzenais para planejamento e organização das propostas. Os encontros ocorrem, geralmente, nos momentos de hora-atividade dos profissionais do magistério ou entre 12:30 e 13:30, horário em que há dois ou três profissionais adultos em cada sala de referência; ou entre 17:45 e 18:30, quando o número de crianças é mais reduzido, sendo possível juntar as turmas, sem prejuízo na qualidade do atendimento às crianças. Encontros também podem ser realizados em pequenos momentos da pauta das Reuniões Pedagógicas.

O trabalho com o tema Africanidades foi proposto ao NEIM por um de seus grupos, o Grupo 3-B (G3-B), que estava trabalhando com histórias e lendas africanas e afro-brasileiras. Esse grupo propôs ampliar sua pesquisa para as demais crianças. A proposta foi acatada pelo grupo de profissionais que participavam do projeto Integração, que buscava ampliar vivências ao coletivo da instituição. Em Reunião Pedagógica a proposta foi apresentada ao coletivo, que aceitou o convite de participar do projeto Africanidades. A partir de então, ela foi estendida aos doze grupos de trabalho do Núcleo de Educação Infantil Municipal (NEIM).

Em Florianópolis, desde o ano de 1994, a lei municipal de número 4.446, instituiu "a inclusão do conteúdo 'História afro-brasileira' nos currículos das escolas municipais de Florianópolis" (ROMÃO, 2009, p. 169). Sendo que, no artigo segundo, essa inclusão define ser destinada às crianças desde a pré-escola, o que legalmente representa os últimos anos da Educação Infantil e todo o Ensino Fundamental, faixa escolar atendida pela educação pública municipal. A título de informação, convém lembrar que após nove anos, no ano de 2003, a lei federal número 10.639, tornou "obrigatório o ensino sobre História e Cultura Afro-brasileira" (BRASIL, 2003, art. 26), e incluiu no calendário escolar "o dia 20 de novembro como ‘Dia Nacional da Consciên- 
cia Negra"' (BRASIL, 2003, art. 79). Portanto, esses conteúdos devem ser apresentados e discutidos como parte do currículo das instituições de ensino, sejam elas públicas ou privadas, tenham elas alunos declarados negros ou não. A história afro-brasileira precisa ser conhecida, valorizada e reconhecida por todos.

No ano de 2016 foi publicada em Florianópolis a Matriz Curricular para a Educação das Relações Étnico-raciais na Educação Básica, no intuito de "traduzir o desejo de uma rede em garantir a igualdade para todos na sua diversidade, baseada no reconhecimento e no respeito às diferenças" (FLORIANÓPOLIS, 2016, p. 7). Ao ampliar a discussão para a educação básica, subentende-se incluídas: a Educação Infantil, o Ensino Fundamental e o Ensino Médio, mediando e realizando esta discussão em seus currículos e propostas pedagógicas, bem como trabalhando conteúdos que reconheçam e valorizem as diferentes culturas.

Trabalhar conceitos referentes à Educação das Relações Étnico-Raciais (ERER) faz parte do currículo da Educação Básica. Desde o trabalho educativo realizado com as crianças da Educação Infantil, o respeito e a valorização a diferentes povos, hábitos e costumes devem ser conversados, problematizados e trabalhados nas instituições educativas. Convém, porém lembrar que passados quinze anos da promulgação da lei federal, Cardoso (2018, p. 93) aponta que "a ERER ainda não é um projeto coletivo das unidades educativas [...] há muito a ser feito". Nós, brasileiros, somos formados por uma infinidade de misturas de povos, de línguas, de costumes, e mesmo assim percebemos no dia-a-dia, nos locais por onde passamos como professores ou visitantes, que muitas instituições educativas propõem práticas de uma cultura única, sem respeito e valorização aos diferentes.

\section{INICIANDO O PLANEJAMENTO DO PROJETO}

A fim de desenvolver o projeto com o coletivo de doze grupos da instituição, os profissionais envolvidos no grupo de trabalho Integração se apoiaram nas dicas de livros de litera- 
tura de temática africana, indicados pela professora do G3-B. Livros que ela pretendia apresentar ao seu grupo de trabalho, e que compuseram o planejamento do coletivo do grupo, que lançou com os livros disponibilizados algumas propostas de ação.

A primeira proposta foi a de fazer circular entre os doze grupos o livro Os sete novelos: um conto de Kwanzaa, de autoria de Angela Medearis (2005), e ilustrações de Daniel Minter. A história, que ressalta a importância da união e compartilhamento da vida em comunidade, foi contada, lida e mostrada pelos adultos aos grupos de crianças. Cada grupo de crianças ouviu a história pela voz de seu professor, e após o conhecimento da história, realizaram uma pintura num pedaço de pano cru, de 50 centímetros quadrados, transformando-o em "ouro". Todos os doze pedaços foram unidos e transformados num painel para decorar a nossa instituição educativa.

O livro acima citado narra a história de um pai negro, viúvo, que tem sete filhos homens. Ao morrer, o pai deixa a cada filho um novelo de lã/linha, e deixa dito que seus filhos terão que transformar aqueles novelos em ouro, para terem direito à herança. Tendo que aprender a trabalhar juntos, os filhos tecem o tecido mais bonito de todos, o qual é vendido numa feira a uma família da realeza. Eles, os filhos, aprendem a força da união e do trabalho coletivo. No caso das crianças, no decorrer da leitura, valores culturais são apresentados e reconhecidos. Elas se encantaram e enfeitaram seus tecidos. Quando o painel foi exposto, elas mostravam orgulhosas aos parentes que as acompanhavam em suas entradas e saídas do NEIM.

De acordo com o registro no caderno do grupo Integração: "escutar uma história, cada qual em seu grupo, pode ser 'atividade comum', que ocorre com certa frequência nas instituições educativas, e são constantemente citadas/contempladas nos planejamentos. Mas aqui, os doze grupos escutaram a mesma história, numa mesma semana". Sim, cada grupo de crianças escutou a história no aconchego de sua sala de referência, na voz do seu professor. E deixaram sua marca num pedaço de tecido. Num painel que ainda hoje decora e conta 
sua história aos que chegam ao NEIM.
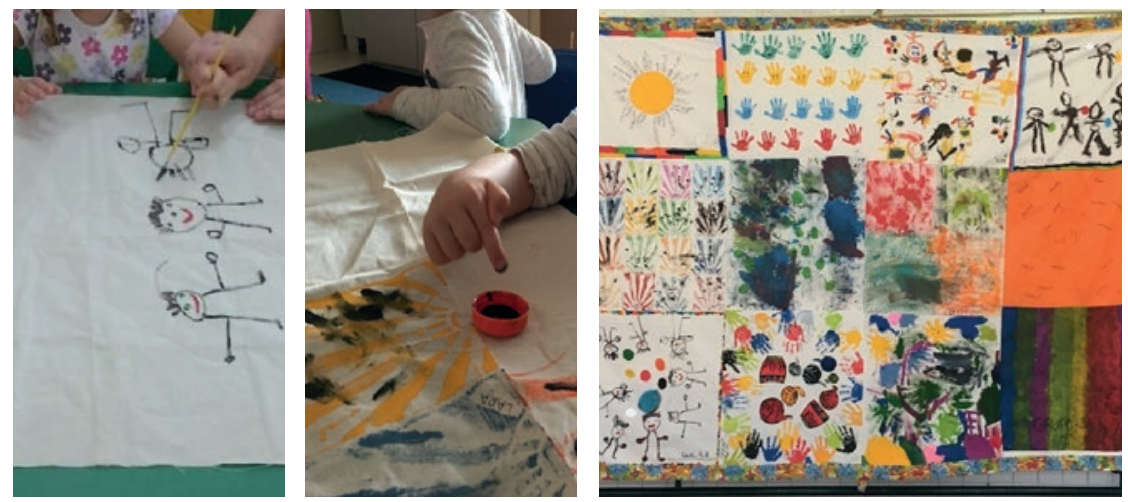

Figura 1: Processo de criação/pintura nas salas e os pedaços costurados no painel

Fonte: arquivo pessoal da autora

Concordando com Diaz e Tonácio (2015, p. 1057) “acreditamos que a partir da educação literária podemos proporcionar [...] outras histórias, outras estéticas, outras formas de enxergar o mundo, desacostumando o nosso olhar do olhar eurocêntrico ao qual estamos acostumados e inseridos". Olhar outras coisas, apreciar outras culturas, perceber outras formas de ilustração, outros coloridos, outros modos de relação. Literatura que propicia outros olhares.

Outro livro também inspirou as ações coletivas com as crianças: Olelê - uma antiga cantiga da África, um conto africano de autoria de Fábio Simões (2015), com ilustrações de Marilia Pirillo. A história deste livro foi encenada por adultos e crianças do NEIM. O livro narra a história de uma cantiga nascida na travessia de todo um povo na época das cheias do rio. "Foi por causa do rio, que a cantiga surgiu" (SIMÕES, 2015). O livro conta da força e da coragem de um povo que a cada ano precisa ensinar suas crianças os perigos do rio, e a necessidade de mudanças para a continuidade da vida e da comunidade. Após a representação da história em forma de teatro de adultos e crianças e da audição da cantiga que embala a travessia, o livro, em sua 
materialidade, foi oferecido às professoras dos doze grupos de crianças que, em forma de revezamento, o fizeram circular para ser manuseado, ouvido e folheado. Nos grupos, adultos e crianças trabalharam detalhadamente o enredo, perceberam as ilustrações, encenaram novas tramas de travessias, exploraram os paratextos que a escrita do autor oferece, cantaram e encenaram a cantiga a seu modo.

No mês de outubro em nosso NEIM, contamos ainda com a apresentação do espetáculo infantil: A fantástica exposição de Zeca, apresentado pelo grupo Trupe da Alegria. No enredo, a Trupe vem fazer uma exposição de livros no NEIM, porém, durante essa, os personagens saem dos livros e apresentam um pouco de suas histórias, culturas e tramas. Personagens de diferentes culturas: do Japão, da Índia, da Europa, da África e do Brasil, além dos tradicionais personagens dos contos de fadas, interagem com a plateia e com os demais personagens. Personagens que invadem a instituição e divertem crianças e adultos como a rainha de copas, a fada Fauna, o lobo mau, o índio da tribo guarani, a princesa Violeta, a feiticeira Kiriku, a benzedeira da Ilha da Magia, os personagens das histórias de Franklin Cascaes, a guerreira da tribo Maori, da Oceania e o trapaceiro Rumpelstiltskin, entre outros.
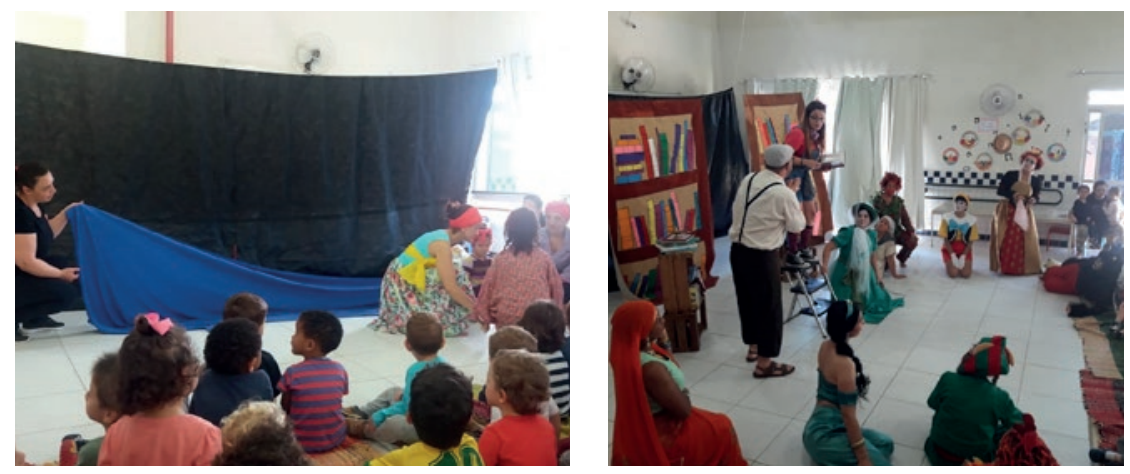

Figura 2: Teatro inspirado no livro Olelê e Teatro a Fantástica Exposição de Zeca

Fonte: arquivo pessoal da autora 
O ponto alto do projeto Africanidades foi a realização de uma Mostra educativa de trabalhos, painéis, oficinas, exposições, entre outros, realizada nos pequenos grupos e apresentada à comunidade educativa, referente aos diferentes enfoques do trabalho com a temática. A Mostra trazia as propostas que foram trabalhadas nos grupos de professores, com as crianças, realizando pesquisas, leituras e experimentos em diferentes campos, para compor um todo chamado Africanidades. Propostas que também foram trazidas para o coletivo, e que foram vivenciadas por outras crianças no espaço educativo de nossa instituição. E é sobre essa Mostra que falaremos a seguir.

\section{ENTRE A MOSTRA EDUCATIVA E AS PESQUISAS: CONHECENDO E APRENDENDO COM AS DIFERENÇAS}

Dia 31 de outubro foi a data escolhida pelo grupo de professores para a realização da Mostra de trabalhos às famílias e à comunidade. Nesse dia foram apresentadas várias atividades e resultados das pesquisas realizadas nos doze grupos sobre a cultura africana e afro-brasileira: danças; culinária, pintura, músicas, literatura, escultura, mapas, bandeiras, contos, costumes, brincadeiras. Algumas destas ideias que surgiram nos pequenos grupos e estavam expostas a todos no período de visitação da Mostra, se propagaram também para o coletivo. Novembro foi, portanto, o mês de visitar os diferentes trabalhos, que ficaram expostos nos corredores e no refeitório da instituição, mês de conversar sobre os trabalhos apresentados com as crianças e também refazer ou brincar/explorar um pouco do que os outros grupos haviam experimentado.

No Grupo 2, formado por crianças de um ano e meio a dois anos e meio de idade, as professoras trabalharam com a produção de colares africanos, feitos em pratos de papelão e decorados com tinta pelas crianças. Os colares que enfeitaram pescoços e cabeças foram expostos do lado de fora da sala, e a atividade de pintura permitiu a expressão de professores e crianças. Muitos dos colares 
foram rasgados, amassados e saboreados pelas crianças. Todos os sentidos foram usados e explorados. Arte de corpo inteiro, com corpo e linguagem se relacionando de modo intenso. Também foram construídos chocalhos com potes de iogurte e mini garrafas de refrigerante do tipo pet, com contas (botões, miçangas), pedras e grãos. Os chocalhos foram expostos dentro de uma caixa plástica, dessas de verdura, e visitaram alguns espaços das diferentes salas de referência da instituição, levados por crianças e seus professores, propiciando a experimentação e diferenciação dos sons mais graves e mais agudos, a depender dos materiais com que eram confeccionados, e acompanharam a cantiga de músicas e melodias conhecidas das crianças.
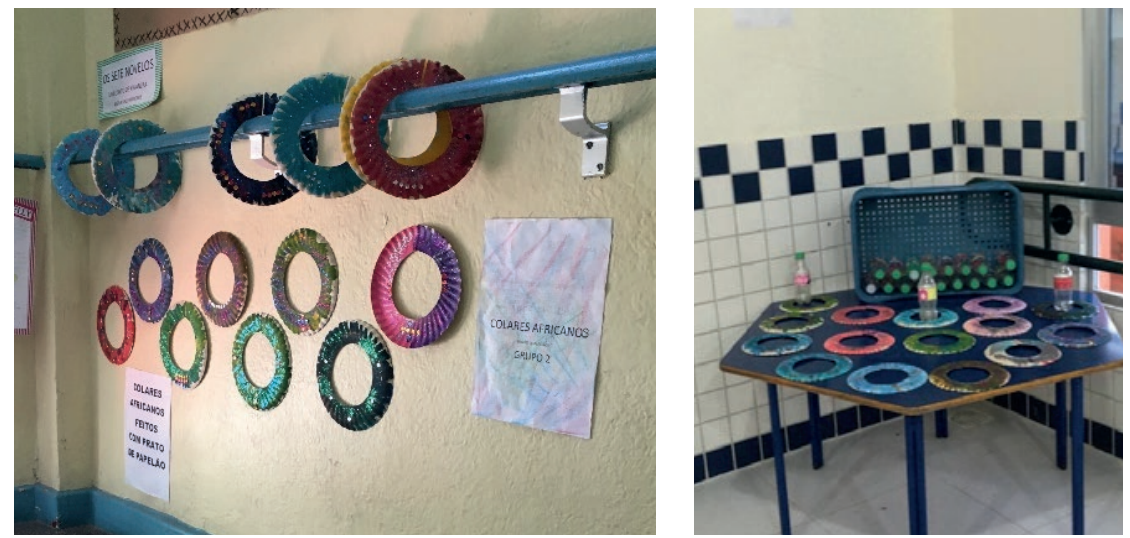

Figura 3: Os colares africanos e os chocalhos ao fundo, a exposição do G2

Fonte: arquivo pessoal da autora

Com crianças de dois anos e meio a três anos e meio, que formam os três grupos nomeados de Grupo 3, foram realizados diferentes trabalhos. Foi contada às crianças uma lenda africana acerca da origem das estrelas e o espaço da sala de referência foi ambientado em conformidade com a lenda. O enredo da história foi encenado pelas crianças e fotografado pelas professoras. As fotos foram impressas e resultaram na produção de um livro a partir das imagens das fotos das crianças, e da reescrita das falas das 
crianças pelas professoras. A história, contada a partir das fotos foi para a parede do corredor do NEIM, e recebeu a visita dos pais e de outras crianças que olhavam os amigos da sala e imaginavam histórias. Fotografias se transformando em arte, sendo expostas, virando livro. Outra possibilidade de linguagem, onde as imagens são ressignificadas e vão além do registro, imagens que compõem um enredo, uma cena e dão asas à imaginação.

Outra história que acompanhou o trabalho no Grupo 3 foi Obax, um texto de ficção, em forma de livro, escrito e ilustrado por André Neves (2010), e ambientado na África. Neste livro, Obax, uma menina negra, e seu elefante Nafisa, são os personagens principais. O encantamento do grupo de crianças pela figura do elefante, levou-as a construir elefantes em forma de dedoche, pintados com esmalte de unha, com os quais brincaram, acompanhando-as nas reinvenções de histórias. O grupo fez uma pesquisa sobre os elefantes, aprendeu sobre as matanças do animal para a extração do marfim, viu que eles transportam pessoas em várias localidades e descobriu que quando eles ficam bem velhinhos se afastam do grupo para morrerem sozinhos. Brincaram de elefante colorido, cantaram a música do elefante que incomoda muita gente, do elefante la' trombita, e do elefante que se balançava na teia da aranha... Músicas, histórias, dedoches e pesquisa. Muita pesquisa.
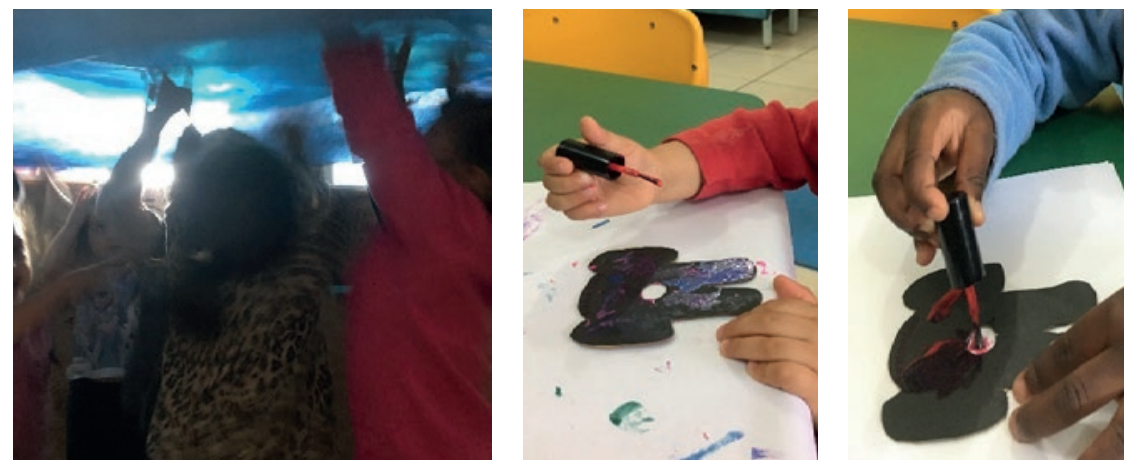

Figura 4: Fazendo as estrelas no céu, uma das fotos do livro e Pintura do elefante com esmalte de unhas

Fonte: arquivo pessoal da autora 
Outra pesquisa foi realizada com as famílias sobre os costumes e hábitos de cada uma delas e, concomitante a isso, o Grupo de trabalho pesquisou costumes e hábitos de alguns povos africanos, o que culminou numa oficina de pintura de rostos e corpos para todos os grupos, no refeitório e no parque de nossa instituição. Pinturas que simbolizam preparação para a caça, participação ou comemoração de um evento, que podem significar amor, beleza e pureza, que podem identificar famílias e clãs, que podem significar a iniciação numa nova fase da vida ou representar uma forma de agradecimento aos antepassados. A pesquisa realizada com as famílias foi exposta com as imagens investigadas pelas professoras e apresentadas no decorrer da pesquisa às crianças. Ambas as pesquisas foram expostas no refeitório. E crianças de diferentes grupos tiveram seus rostos, braços, pernas pintadas, bem como pintaram/marcaram seus amigos com pintura de rosto, num momento de celebração e de encontro entre todos os grupos.
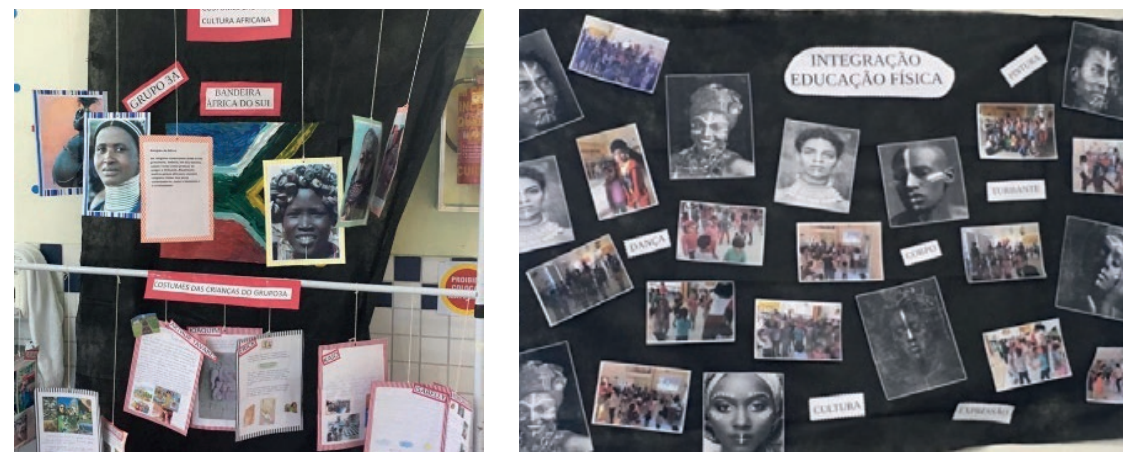

Figura 5: Resultado da pesquisa sobre hábitos e costumes.

Fonte: arquivo pessoal da autora

Nos Grupos 4, o trabalho foi realizado a partir da música, da literatura e da culinária. Instrumentos musicais foram construídos: tambores de lata, chocalhos de garrafa pet, chocalhos de pé com peças presas por um elástico para fazer barulho quando movimentadas, reco-recos com garrafas e madeiras. Além da confecção dos 
instrumentos com material alternativo, foi propiciado ao grupo o contato com instrumentos musicais reais do acervo da instituição ou de pessoas que os trouxeram para o conhecimento de todos, como o berimbau, com o qual fomos chamados a brincar, a jogar e a dançar capoeira. Foi colocado à exploração o afoxé, o caxixi, cuícas, maracás, reco-reco, clavas, sendo que estas foram usadas para a realização da dança ou jogo do maculelê.

Ainda foram pesquisadas comidas de origem africana, e aquelas que foram sendo criadas com a mistura dos ingredientes e temperos brasileiros com o conhecimento culinário e cultural dos africanos. Comidas como o acarajé, o vatapá, o quibebe, o pirão, o angu, a feijoada. E um dos grupos colocou as mãos à obra e serviu a todos no dia da mostra educativa um delicioso docinho de amendoim.

A literatura também se fez presente na exploração do livro Olelê: uma antiga cantiga da África. As professoras trouxeram a música apresentada no livro e as crianças brincaram com a exploração dos movimentos de seus corpos na dança, no falar das palavras de outros povos: moliba, macassi, olelê, cassaí. Fizeram barcos de papel, e brincaram com o barco utilizado na dramatização da história. Construíram um painel com dobraduras de barcos e a foto de cada criança navegando seu barco na travessia. Conforme afirma Debus (2017, p. 38) “o texto literário partiIha com os leitores, independente da idade, valores de natureza social, cultural, histórica e/ou ideológica por ser uma realização da cultura e estar integrado num processo comunicativo".
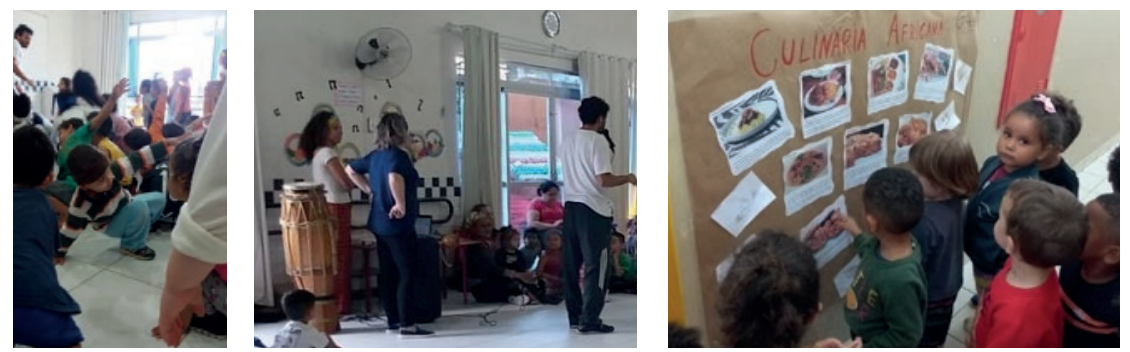

Figura 6: Oficina de dança, apresentação de instrumentos musicais, e painel sobre culinárias

Fonte: arquivo pessoal da autora 
Os grupos 5 e 6 fizeram pesquisas sobre as máscaras africanas, e das máscaras surgiu a possibilidade de pintura coletiva de diferentes tipos, coladas no papel pardo e espalhadas pelas paredes de nosso NEIM. Outro trabalho realizado nestes grupos foi a pesquisa sobre as Abayomis, sendo que esta serviu à realização da atividade coletiva de contação da história realizada por uma das professoras acerca da travessia dos povos africanos para o continente americano. Na história, a professora contou às crianças da esperança da boneca, enquanto um acalanto às crianças que atravessaram o Oceano Atlântico em tempos de exploração e sofrimento. Posterior à contação da história, houve a realização da oficina de chaveiros com as bonecas, que contou com a participação de alguns familiares que se propuseram a vir ao NEIM, e um cartaz sobre o modo de fazer as bonecas foi exposto, pois os pais queriam saber o modo de fazê-las.
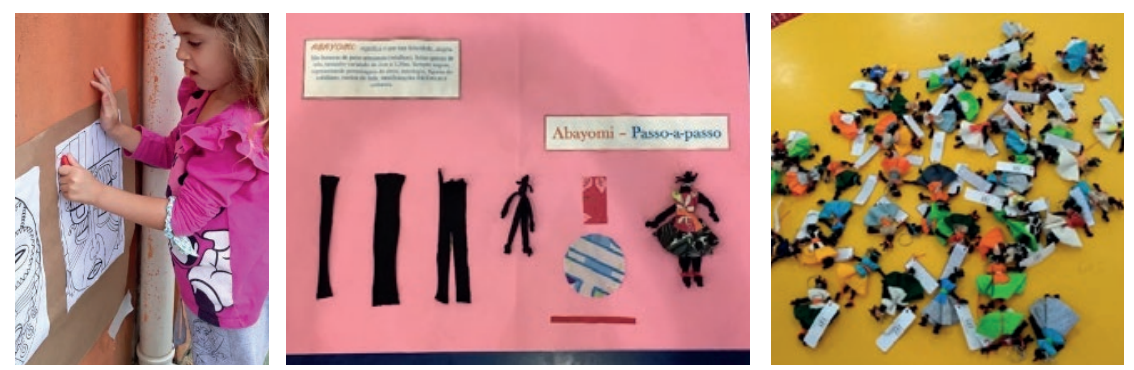

Figura 7: Pintura de máscaras nos espaços externos do NEIM, cartaz sobre as Abayomis

Fonte: arquivo pessoal da autora

Nos Grupos 6 foi realizada a pesquisa sobre a capoeira e o maculelê, que culminou com a apresentação do grupo de crianças com as professoras da sala de referência e de educação física. As crianças se apresentaram no dia da abertura da Mostra educativa às famílias que se faziam presentes nesta data, e a todos os grupos do NEIM que foram para o refeitório participar deste momento de integração. Dança, jogo, brincadeira, movimento. Depois da apresentação todos, adultos e crianças, dan- 
çamos e jogamos capoeira no refeitório. E o maculelê teve seus dias de brincadeiras no parque e na quadra do NEIM.

Também foi realizada a pesquisa e a oficina de produção de esculturas com argila. Em um painel, o grupo colocou imagens de produtos feitos com argila, imagens próprias confeccionando seus objetos de argila e imagens do trabalho feito a partir do filme Kiriku e a feiticeira.
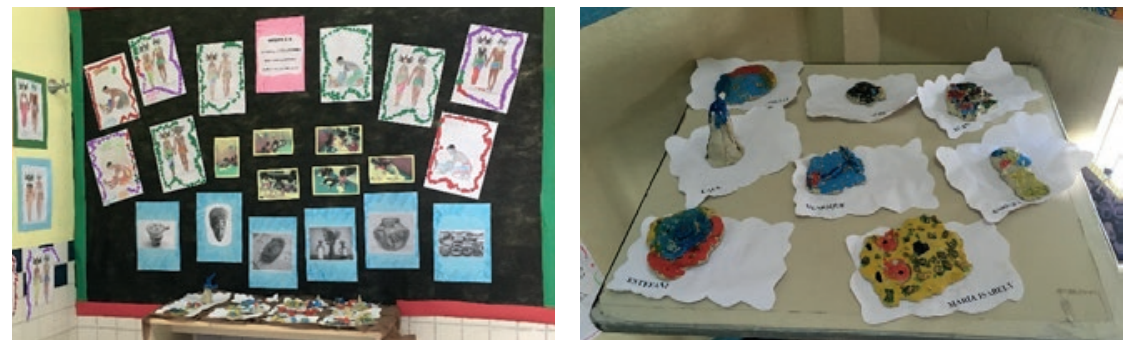

Figura 8: Painel de fotos do grupo e das pesquisas realizadas e destaque às produções em argila

Fonte: arquivo pessoal da autora

\section{PARA TERMINAR E ENCERRAR A CONVERSA, OU REINICIAR NOVAS TRAMAS...}

No decorrer de todo o processo de planejamento das atividades coletivas, pensou-se em propor atividades nas quais fossem possibilitadas às crianças e aos adultos que com elas convivem experiências educativas. Na perspectiva do grupo de professores essas eram vivências significativas, marcantes e de possibilidades múltiplas de exploração, descoberta e brincadeiras. Planejar na educação infantil, requer propor situações de descoberta, de encantamento, de múltiplas linguagens. Trata-se de possibilitar a vivência de situações em que se possa brincar, conhecer, fantasiar e criar. E planejar num coletivo, um único projeto para toda uma instituição, requer comprometimento, parcerias e pesquisas. Como retrata Ostetto (2000, p. 25) “o trabalho coletivo não se decreta, ele é construído. E para ser construído depende dos desejos e das atitudes de seus componentes". Podemos 
dizer que neste projeto o envolvimento de todos foi de fundamental importância ao alcance dos objetivos.

Materialidades e múltiplas linguagens foram trabalhadas e exploradas neste projeto que conseguiu de modo efetivo abraçar toda a comunidade educativa. Dentre as linguagens, destacamos: música, canto, dança, teatro, desenho, pintura, escultura, recortes, colagens, animações, vídeos, sonoridades, faz-de-contas, escritas, poesias, brincadeiras, literatura... Corpo e linguagem relacionaram-se de modo íntimo e ampliaram as possibilidades de exploração e descoberta do corpo, do movimento, do conhecimento, na vivência de múltiplas linguagens humanas. Linguagens da arte e da vida. Linguagens que nos constituem e que nos permitem entender melhor nossa cultura e as várias culturas de inúmeros povos e grupos que conosco vivem e convivem.

De acordo com Corsino (2009, p. 8) "nada como a arte para aproximar o homem dele mesmo e do outro. A arte, nas suas mais diferentes manifestações: desenho, pintura, escultura, teatro, músi$\mathrm{ca}$, cinema, literatura, traz as sutilezas e riquezas do homem como indivíduo e como parte de um contexto sociocultural". A arte nos afeta, nos provoca descobertas, conhecimentos, sentimentos, nos coloca em relação. Nos permite olhar com outros olhos e perceber que cada olhar é único, individual e merecedor de atenção, respeito e valorização. Assim como cada indivíduo é único e especial.

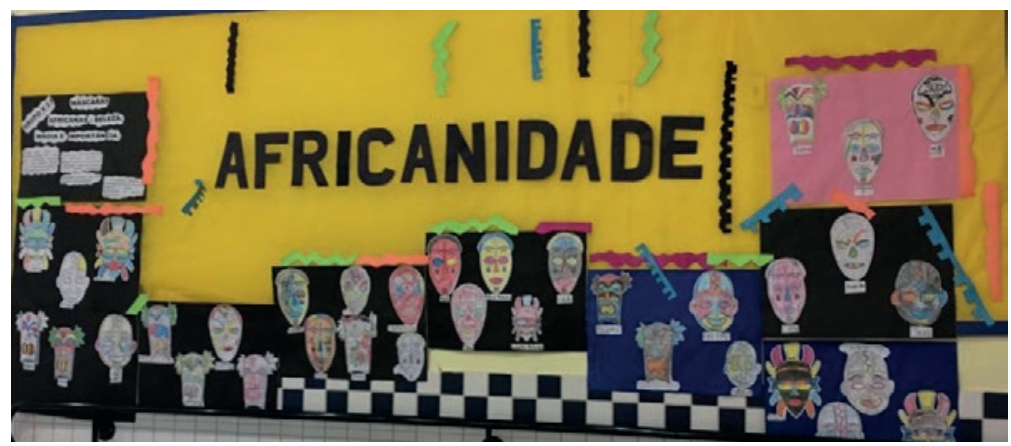

Figura 9: painel de chamada à exposição

Fonte: arquivo pessoal da autora 


\section{REFERÊNCIAS}

BRASIL. Presidência da República. Lei federal n. 10.639, de 9 de janeiro de 2003. Altera a lei n0 9394, de 20 de dezembro de 1996, que estabelece as diretrizes e bases da educação nacional, para incluir no currículo oficial da rede de ensino a obrigatoriedade da temática "História e cultura afro-brasileira" e dá outras providências. Diário Oficial da União, Brasília, DF, 2003.

BRASIL. Ministério da Educação. Secretaria Especial de Políticas de Promoção da Igualdade Racial. Diretrizes curriculares nacionais para a educação das relações étnico-raciais e para o ensino da história e cultura afro-brasileira e africana. Brasil, 10 de março de 2004.

CARDOSO, Cintia. Branquitude na educação infantil: um estudo sobre a educação das relações étnico-raciais em uma unidade educativa do município de Florianópolis. Dissertação (Mestrado em Educação). Curitiba, PPGE, Universidade Federal do |Paraná, 2018.

CORSINO, Patricia. Introdução. In: CORSINO, Patricia (org). Educação Infantil: cotidiano e políticas. Campinas, SP, Autores associados, 2009. p. 01-13.

CORSINO, Patricia. Trabalhando com projetos na educação infantil. In: CORSINO, Patricia (org). Educação Infantil: cotidiano e políticas. Campinas, SP, Autores associados, 2009. p. 105-121.

DEBUS, Eliane. A temática da cultura africana e afro-brasileira na literatura para crianças e jovens. Florianópolis - SC, NUP/ CED/UFSC, 2017.

DIAS, Mariane Del Carmen da Costa. TONACIO, Gloria de Melo. Educação literária para a educação das relações etnicorraciais: reflexões se algumas práticas docentes. In: ANAIS IV Congresso Internacional de Literatura Infantil e Juvenil: celebrando a leitura. Presidente Prudente, 2015. p. 1050-1063. 
FLORIANÓPOLIS, Prefeitura Municipal. Secretaria Municipal de Educação. Matriz Curricular para a educação das relações étnico-raciais na educação básica. Florianópolis, SC, 2016.

MEDEARIS, Angela Shelf. Os sete novelos: um conto de Kwanzaa. Tradutor: André Jenkino do Carmo. Ilustrador: MINTER, Daniel. São Paulo, Cosac Naify, 2005.

NEVES, André. Obax. São Paulo, Brinque-book, 2010.

OSTETTO, Luciana Esmeralda. Andando por creches e préescolas públicas: construindo uma proposta de estágio. In: OSTETTO, L.E. (Org.). Encontros e encantamentos na educação infantil: partilhando experiências de estágios. Campinas, São Paulo, Papirus, 2000. p. 15-30.

ROMÃO, Jeruse Maria. A África está em nós: história e cultura afro-brasileira: africanidades catarinenses, volume 5. João Pessoa - PB, Editora Grafset, 2009.

SIMÕES, Fábio. Olelê: uma antiga cantiga da África. Ilustradora: PIRILLO, Marília. São Paulo, Melhoramentos, 2015. 